\title{
Separation of minor actinides from lanthanides using immobilized ligand systems: the role of the counterion
}

Article

Accepted Version

Afsar, A., Distler, P., Harwood, L., John, J., Babra, J. S., Selfe, Z., Cowell, J. and Westwood, J. (2019) Separation of minor actinides from lanthanides using immobilized ligand systems: the role of the counterion. Heterocycles, 99 (2). pp. 825-833. ISSN 1881-0942 doi: https://doi.org/10.3987/COM-18-S(F)71 Available at https://centaur.reading.ac.uk/80779/

It is advisable to refer to the publisher's version if you intend to cite from the work. See Guidance on citing.

To link to this article DOI: http://dx.doi.org/10.3987/COM-18-S(F)71

Publisher: The Japan Institute of Heterocyclic Chemistry

All outputs in CentAUR are protected by Intellectual Property Rights law, including copyright law. Copyright and IPR is retained by the creators or other copyright holders. Terms and conditions for use of this material are defined in the End User Agreement.

www.reading.ac.uk/centaur 
Central Archive at the University of Reading

Reading's research outputs online 


\begin{abstract}
HETEROCYCLES, Vol. , No. , , pp. -. (c) The Japan Institute of Heterocyclic Chemistry
Received, , Accepted, , Published online,

DOI: 10.3987/COM- (Please do not delete.)

SEPARATION OF MINOR ACTINIDES FROM LANTHANIDES USING

IMMOBILIZED LIGAND SYSTEMS: THE ROLE OF THE

COUNTERION
\end{abstract}

\title{
Ashfaq Afsar, ${ }^{a}$ Petr Distler, ${ }^{\mathrm{b}}$ Laurence M. Harwood, ${ }^{a^{*}}$ Jan John, ${ }^{\mathrm{b}}$ Jasraj S.

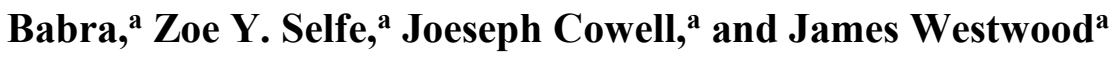

a. Chemical Sciences Division, University of Reading, Whiteknights, Reading, Berkshire RG6 6AD, UK. E-mail: 1.m.harwood@reading.ac.uk

b. Department of Nuclear Chemistry, Czech Technical University in Prague, Břehová 7, 11519 Prague 1, Czech Republic. E-mail: jan.john@fjfi.cvut.cz

\begin{abstract}
A} \mathrm{CyMe}_{4}-\mathrm{BTPhen}$ functionalized silica gel that selectively extracts Am(III) over $\mathrm{Eu}(\mathrm{III})$ from $4 \mathrm{M} \mathrm{HNO} 3$ with a separation factor $>154$ has been developed. Evidence is presented that the counterion surrounding the M(III) in the proposed 1:1 [BTPhen:M(III)] complex plays an important role in the complexation of $\mathrm{Am}(\mathrm{III})$ and $\mathrm{Eu}(\mathrm{III})$.
\end{abstract}

Separation of minor actinides $(\mathrm{Am} / \mathrm{Cm})$ from lanthanides is a key step in the reduction of radiotoxicity and thermal emission of nuclear waste. ${ }^{1}$ The removal of these elements, which account for $\sim 0.1 \%$ by mass but for $\sim 90 \%$ long-lived radiotoxicity of the waste could reduce both the duration of the radiological hazard and the volumes of high-level waste. ${ }^{2,3}$ One proposed approach currently being studied for the long-term management of high-level waste after PUREX (plutonium and uranium redox extraction) reprocessing currently used in Europe is to separate the minor actinides (An) from the lanthanides (Ln); after which an can be transmuted into short-lived radionuclides or stable nonradioactive elements using high-energy neutrons in a generation iv reactor. ${ }^{4-9}$ However, this separation is very difficult given the similar chemical properties of the Am(iii), $\mathrm{Cm}$ (iii) and $\mathrm{Ln}$ (iii). ${ }^{10}$

Nevertheless, previous studies have shown that soft $N$-donor ligands containing the 1,2,4-triazine moiety (Figure. 1) are capable of separating An(III) from Ln(III) in a solvent-based SANEX (Selective ActiNide EXtraction) process. ${ }^{11-13}$ The selectivity of these reagents for An(III) over $\operatorname{Ln}(\mathrm{III})$ is believed to arise from a larger degree of covalency in the $\mathrm{An}(\mathrm{III})-N$ bond. ${ }^{14-16}$ Bis-(1,2,4-triazine) molecules, such as the tridentate 2,6-bis(1,2,4-triazine-3-yl)pyridines (BTPs), and the quadridentate 6,6'-bis(1,2,4-triazin-3-yl)- 
2,2'-bipyridines (BTBPs) depicted in Figure. 1, show high selectivities, with 2,9-bis(5,5,8,8-tetramethyl5,6,7,8-tetrahydrobenzo[1,2,4]triazin-3-yl)-1,10-phenanthroline (CyMe4-BTPhen 3) showing optimum extraction performance in the laboratory to date. ${ }^{17-20}$

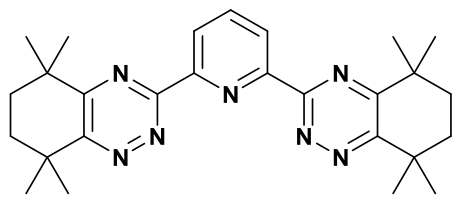

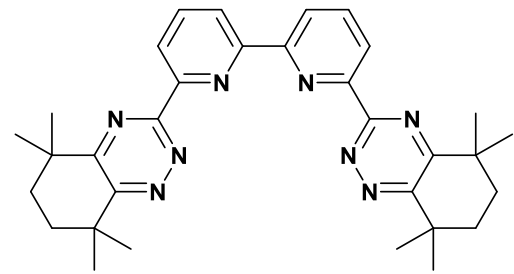

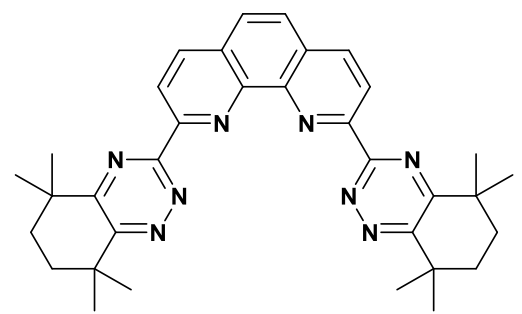

Figure 1. Structural formulae of CyMe $\mathrm{C}_{4}$-BTP 1, CyMe 4 -BTBP 2 and $\mathrm{CyMe}_{4}-\mathrm{BTPhen} 3$

Although several other partitioning processes ${ }^{21}$ have also been proposed and studied to separate An(III) from $\mathrm{Ln}(\mathrm{III})$, most of these processes utilize liquid-liquid extraction technology that brings certain disadvantages, in particular requiring large volumes of organic solvents, which can become degraded, reducing performance and needing to be disposed as secondary waste. ${ }^{22-25}$ Furthermore, liquid-liquid extraction processes often require phase modifiers and can encounter problems with third phase formation. ${ }^{26}$ To overcome the disadvantages of liquid-liquid extraction, systems based on solid phase extractants have been proposed. ${ }^{23-28}$ We have recently developed and reported magnetic nanoparticle (MNP) and silica gel-based solid phase extractants (Figure. 2), where we have demonstrated that immobilized BTPhen type ligands could be used either to extract both An(III) and Ln(III) at low concentrations of $\mathrm{HNO}_{3}$ or to extract $\mathrm{An}(\mathrm{III})$ selectively over $\mathrm{Ln}(\mathrm{III})$ at high concentrations of $\mathrm{HNO}_{3}{ }^{29,30}$

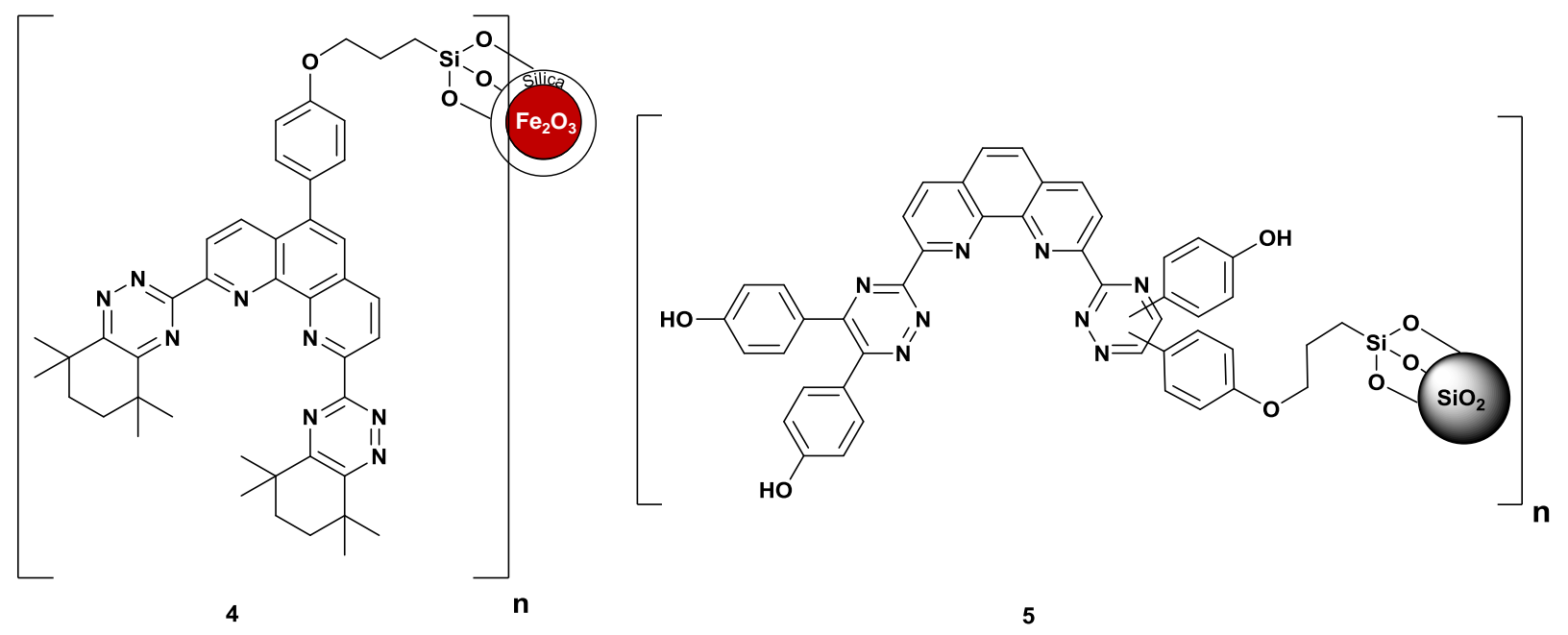

Figure 2. Structural formulae of $\mathrm{CyMe}_{4}$-BTPhen-functionalized $\mathrm{SiO}_{2}$-coated $\mathrm{MNP} 4$ and tetra(4hydroxyphenyl)-BTPhen-functionalized $\mathrm{SiO}_{2}$ gel 5 
Previously, we reported a partitioning process for minor actinides and lanthanides based on a column separation technique using the novel tetra(4-hydroxyphenyl)-BTPhen-functionalized $\mathrm{SiO}_{2}$ gel $\mathbf{5} .{ }^{29}$ Herein, we report the synthesis and extraction properties of a new CyMe4-BTPhen-functionalized $\mathrm{SiO}_{2}$ gel 8 and investigations into the nature of the counterion influence on extraction efficiency.

The (4-hydroxyphenyl) functionalized $\mathrm{CyMe}_{4}-\mathrm{BTPhen}$ ligand 6 was synthesized following a previously described protocol and was then immobilized onto commercially available chloropropyl-functionalized $\mathrm{SiO}_{2}$ gel 7 as shown in Scheme $1 .^{30}$

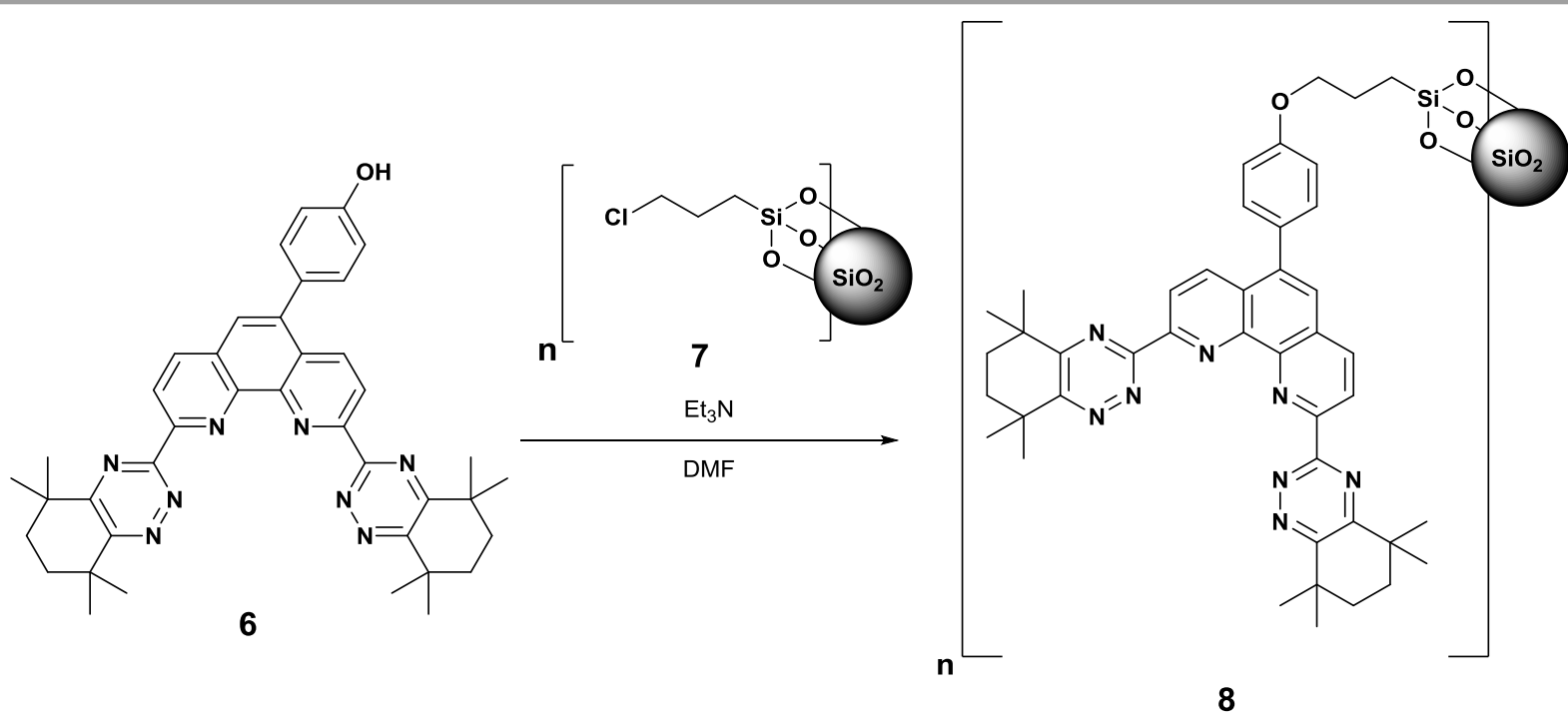

Scheme 1. Immobilization of (4-hydroxyphenyl) functionalized CyMe $\mathrm{C}_{4} \mathrm{BTPhen} \mathbf{6}$ on silica gel

Fourier transform infrared spectroscopy (FT-IR), elemental analysis (EA) and thermogravimetric analysis (TGA) were used to assess the degree of incorporation of ligand 6 onto the silica surface. The presence of absorption bands at $1500-1600 \mathrm{~cm}^{-1}$ assigned to $\mathrm{C}=\mathrm{C}$ aromatic vibrations in the FT-IR spectrum (ESI $\dagger$ ) for 8 provided evidence of the covalent functionalization of 6 onto the $\mathrm{SiO}_{2}$ surface. EA (ESI $\dagger$ ) showed an increase in the content of $\mathrm{CHN}$ compared to chloropropyl-functionalized $\mathrm{SiO}_{2}$ gel 7 and TGA (ESI $\dagger$ ) allowed the determination of the degree of surface modification through comparison of the relative mass loss compared to 7 indicating that the content of $\mathbf{6}$ in the $\mathrm{CyMe}_{4}-\mathrm{BTPhen}$-functionalized $\mathrm{SiO}_{2}$ gel 8 was $25 \% \mathrm{w} / \mathrm{w}$.

In the initial investigations, the aqueous solutions for the immobilized ligand extraction experiments were prepared by spiking nitric acid $\left(\mathrm{HNO}_{3}\right)$ and perchloric acid $\left(\mathrm{HClO}_{4}\right)$ solutions $(0.001-4 \mathrm{M})$ with stock 
solutions of ${ }^{241} \mathrm{Am}$ and ${ }^{152} \mathrm{Eu}$ and then adding $1 \mathrm{~mL}$ of the spiked aqueous solution to an accurately weighed amount of $\mathrm{CyMe}_{4}-\mathrm{BTPhen}$-functionalized $\mathrm{SiO}_{2}$ gel 8 or $\mathrm{CyMe}_{4}-\mathrm{BTPhen}$ functionalized $\mathrm{SiO}_{2}-$ coated MNPs 4. The suspensions were sonicated for $10 \mathrm{~min}$ and shaken at $1800 \mathrm{rpm}$ for $90 \mathrm{~min}$. After centrifuging for $10 \mathrm{~min}$, aliquots of the supernatant were separated and taken for gamma measurements. The weight distribution ratios are defined as $D_{\mathrm{w}}=\left(I_{0}-I\right) / I . V / m$, where $I_{0}$ and $I$ were initial and final count rates in the taken standard/aliquot, $V$ is a volume of an aqueous phase shaken and $m$ is a mass of the material 8 or 4 . The separation factor is $S F_{\mathrm{Am} / \mathrm{Eu}}=D_{\mathrm{wAm}} / D_{\mathrm{wEu}}$.

Extractions were studied at $\mathrm{HNO}_{3}$ and $\mathrm{HClO}_{4}$ concentrations of $0.001 \mathrm{M}, 0.1 \mathrm{M}, 1 \mathrm{M}$ and $4 \mathrm{M}$. The weight distribution ratios $\left(D_{\mathrm{wAm}}\right.$ and $\left.D_{\mathrm{wEu}}\right)$ and separation factors for $\mathrm{Am}(\mathrm{III})$ over Eu(III) $\left(S F_{\mathrm{Am} / \mathrm{Eu}}\right)$ for CyMe $4-B T P h e n-f u n c t i o n a l i z e d ~ \mathrm{SiO}_{2}$ gel 8 as a function of $\mathrm{HNO}_{3}$ concentration are shown in Figure. 3. High weight distribution ratios $\left(D_{\mathrm{w}}>160\right)$ were obtained for both $\mathrm{Am}(\mathrm{III})$ and $\mathrm{Eu}(\mathrm{III})$ at $0.001 \mathrm{M} \mathrm{HNO}_{3}$ solution with no significant selectivity $\left(S F_{\mathrm{Am} / \mathrm{Eu}}=1.1 \pm 0.1\right)$ for $\mathrm{Am}(\mathrm{III})$ over $\mathrm{Eu}(\mathrm{III})$. At $0.1 \mathrm{M} \mathrm{HNO}_{3}$, there was an increase in $D_{w}$ values for both $\mathrm{Am}(\mathrm{III})\left(D_{w \mathrm{Am}}=11630 \pm 2033\right)$ and $\mathrm{Eu}(\mathrm{III})\left(D_{w \mathrm{Eu}}=5618 \pm\right.$ 720) resulting in $S F_{\mathrm{Am} / \mathrm{Eu}}=2.1 \pm 0.4$. Subsequently, decreases in the $D_{w}$ values for both Am(III) and $\mathrm{Eu}(\mathrm{III})$ were observed $\left(D_{w \mathrm{Am}}=3813 \pm 384, D_{w \mathrm{Eu}}=63.9 \pm 2.3\right)$ at $1 \mathrm{M} \mathrm{HNO}_{3}$ solution, but now a higher separation factor $\left(S F_{\mathrm{Am} / \mathrm{Eu}}=60 \pm 6\right)$ resulted. Finally, at $4 \mathrm{M} \mathrm{HNO}_{3}$, although a decrease in $D_{\mathrm{w}}$ value for Am (III) gave $D_{\text {wAm }}=354 \pm 12$; the $D_{\text {w }}$ value observed for $\mathrm{Eu}(\mathrm{III})$ was $<2.3$ and the resulting separation factor was $S F_{\mathrm{Am} / \mathrm{Eu}}>154$.

The reduction in $D_{\mathrm{w}}$ with increasing $\left[\mathrm{HNO}_{3}\right]$ for $\mathrm{CyMe}-\mathrm{BTPhen}$-functionalized $\mathrm{SiO}_{2}$ gel 8 was also previously observed for $\mathbf{4}$ and $\mathbf{5}$ and may, to some extent, be attributed to the increased degree of ligand protonation and thus decreased free ligand concentration. ${ }^{29,30}$ The effect of $\mathrm{HNO}_{3}$ concentration on the degree of extraction of $\mathrm{Am}(\mathrm{III})$ and $\mathrm{Eu}(\mathrm{III})$ also mirrors that of $\mathbf{4}$ and $\mathbf{5}$, where it was concluded that the limited length of the linking-chain on the MNP/silica gel forced the quadridentate BTPhen ligand to form a 1:1 complex with 10 -coordinate $\mathrm{M}$ (III) cations. ${ }^{29,30}$ Thus, whilst the decreasing $\mathrm{pH}$ affected the extraction of both $\mathrm{Am}(\mathrm{III})$ and $\mathrm{Eu}(\mathrm{III})$, we were intrigued by the possibility that it might be the nature of the counterion surrounding the $\mathrm{M}(\mathrm{III})$ species in the 1:1 complex that was leading to the increasing distinction between $\mathrm{Am}(\mathrm{III})$ from $\mathrm{Eu}(\mathrm{III})$ at increasing $\mathrm{HNO}_{3}$ concentration.

The effect of $\mathrm{HNO}_{3}$ concentration on the degree of extraction of Am(III) and Eu(III) also mirrors that of 4 and 5, where it was concluded that the limited length of the linking-chain on the MNP/silica gel forced the quadridentate BTPhen ligand to form a 1:1 complex with 10-coordinate M(III) cations. ${ }^{29,30}$ Thus, whilst the decreasing $\mathrm{pH}$ affected the extraction of both $\mathrm{Am}(\mathrm{III})$ and $\mathrm{Eu}(\mathrm{III})$, we were intrigued by the possibility that it might be the nature of the counterion surrounding the M(III) species in the 1:1 complex 
that was leading to the increasing distinction between $\mathrm{Am}(\mathrm{III})$ from $\mathrm{Eu}(\mathrm{III})$ at increasing $\mathrm{HNO}_{3}$ concentration.

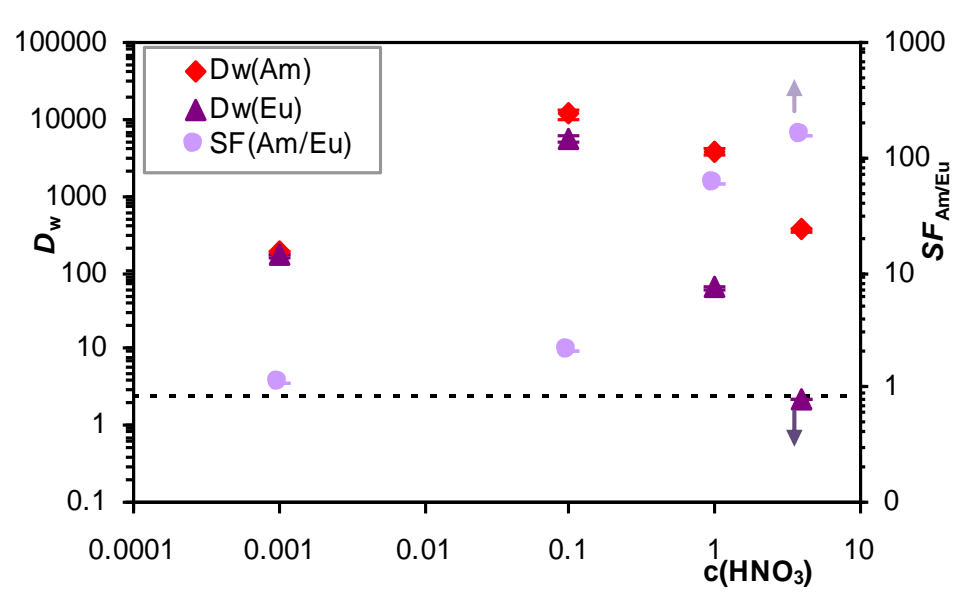

Figure 3. Extraction of $\mathrm{Am}(\mathrm{III})$ and $\mathrm{Eu}(\mathrm{III})$ by $\mathrm{CyMe}-\mathrm{BTPhen}$-functionalized $\mathrm{SiO}_{2}$ gel $\mathbf{8}$ as a function of $\mathrm{HNO}_{3}$ concentration. Mass of sorbent: approximately $16 \mathrm{mg}$, phase volume: $1 \mathrm{~mL}, \mathrm{~V} / \mathrm{m}$ ratio: $\sim 60 \mathrm{~mL} \mathrm{~g}^{-1}$

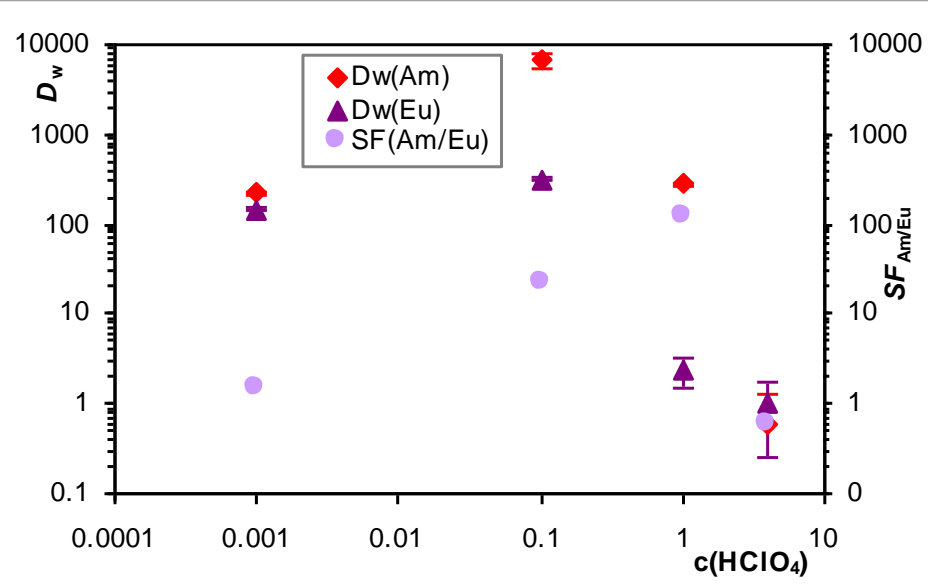

Figure 4. Extraction of $\mathrm{Am}(\mathrm{III})$ and $\mathrm{Eu}(\mathrm{III})$ by $\mathrm{CyMe}$-BTPhen-functionalized $\mathrm{SiO}_{2}$ gel 8 as a function of $\mathrm{HClO}_{4}$ concentration. Mass of sorbent: approximately $15 \mathrm{mg}$, phase volume: $0.6 \mathrm{~mL}, \mathrm{~V} / \mathrm{m}$ ratio: $\sim 40 \mathrm{~mL}$ $\mathrm{g}^{-1}$

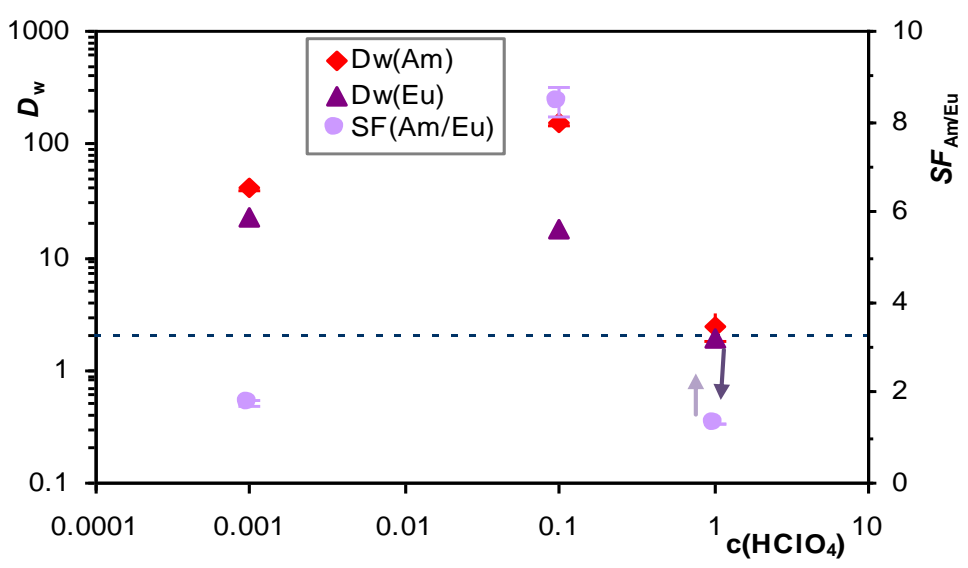

Figure 5. Extraction of $\mathrm{Am}(\mathrm{III})$ and $\mathrm{Eu}(\mathrm{III})$ by $\mathrm{CyMe}_{4}$-BTPhen-functionalized $\mathrm{SiO}_{2}$-coated $\mathrm{MNPs} 4$ as a 
function of $\mathrm{HClO}_{4}$ concentration. Mass of sorbent: approximately $18 \mathrm{mg}$, phase volume: $0.6 \mathrm{~mL}, \mathrm{~V} / \mathrm{m}$ ratio: $33 \mathrm{~mL} \mathrm{~g}^{-1}$

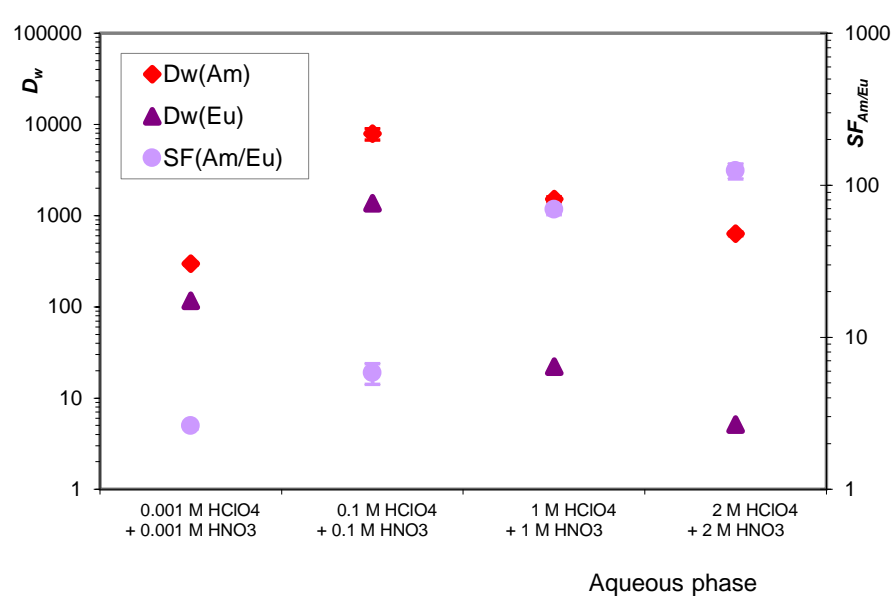

Figure 6. Extraction of $\mathrm{Am}(\mathrm{III})$ and $\mathrm{Eu}(\mathrm{III})$ by $\mathrm{CyMe}_{4}-\mathrm{BTPhen}$-functionalized $\mathrm{SiO}_{2}$ gel $\mathbf{8}$ as a function of $\mathrm{HClO}_{4} / \mathrm{HNO}_{3}$ concentration. Mass of sorbent: approximately $15 \mathrm{mg}$, phase volume: $0.6 \mathrm{~mL}, \mathrm{~V} / \mathrm{m}$ ratio: $\sim 40 \mathrm{~mL} \mathrm{~g}^{-1}$

In order to probe whether the counterion exerts an influence on extraction efficiency, the extraction experiments were repeated, but replacing $\mathrm{HNO}_{3}$ with $\mathrm{HClO}_{4}$. Figure. 4 and Figure. 5 show weight distribution ratios for $\mathrm{Am}(\mathrm{III})$ and $\mathrm{Eu}(\mathrm{III})\left(D_{\mathrm{wAm}}\right.$ and $\left.D_{\mathrm{wEu}}\right)$ and separation factors for $\mathrm{Am}(\mathrm{III})$ over $\mathrm{Eu}(\mathrm{III})\left(\mathrm{SF}_{\mathrm{Am} / \mathrm{Eu}}\right)$ for $\mathrm{CyMe}_{4}-\mathrm{BTPhen}$-functionalized $\mathrm{SiO}_{2}$ gel 8 and $\mathrm{CyMe}_{4}-\mathrm{BTPhen}_{\text {-functionalized } \mathrm{SiO}_{2}-}$ coated MNPs 4 as a function of $\mathrm{HClO}_{4}$ concentration $(0.001 \mathrm{M}-4 \mathrm{M})$, respectively. Similarly, to its behaviour in $\mathrm{HNO}_{3}$, for $\mathrm{CyMe}_{4}-\mathrm{BTPhen}$-functionalized $\mathrm{SiO}_{2}$ gel 8 (Figure. 4), the $D_{\mathrm{w}}$ values for both $\mathrm{Am}(\mathrm{III})$ and $\mathrm{Eu}(\mathrm{III})$ initially increased, achieving maximum values at $0.1 \mathrm{M} \mathrm{HClO}_{4}$, and then decreased with increasing $\mathrm{HClO}_{4}$ concentration, in agreement with the earlier results. Even though high $D_{\mathrm{w}}$ values were obtained for both $\mathrm{Am}(\mathrm{III})\left(D_{w \mathrm{Am}}=221 \pm 9\right.$ and $\left.D_{w \mathrm{Am}}=6864 \pm 1298\right)$ and $\mathrm{Eu}(\mathrm{III})\left(D_{w \mathrm{Eu}}=145 \pm 5\right.$ and $D_{w \mathrm{Eu}}=312 \pm 14$ ) at $0.001 \mathrm{M}$ and $0.1 \mathrm{M} \mathrm{HClO}_{4}$ concentrations, all the values (except for those at $0.001 \mathrm{M} \mathrm{HClO}_{4}$ ) are significantly lower than those measured in $\mathrm{HNO}_{3}$. In this case the separation factors were calculated as $S F_{\mathrm{Am} / \mathrm{Eu}}=1.5 \pm 0.1,22.0 \pm 2.6,119 \pm 27$ and $\sim 1$ at 0.001, 0.1, 1 and $4 \mathrm{M} \mathrm{HClO}_{4}$, respectively. When comparing 8 in $\mathrm{HNO}_{3}$ and $\mathrm{HClO}_{4}$, the absence of the $\mathrm{NO}_{3}{ }^{-}$counterion decreases the values of $D_{\mathrm{w}}$, especially at higher acid concentrations. This can be taken as support for the proposal that the bidentate properties of the nitrate ion play an important role in $\mathrm{Am}(\mathrm{III})$ and $\mathrm{Eu}(\mathrm{III})$ separation. The separation factors $S F_{\mathrm{Am} / \mathrm{Eu}}$ are similar in nitric and perchloric acids except for the case of $4 \mathrm{~mol} / \mathrm{L}$ concentration where the substitution of $\mathrm{HNO}_{3}$ with $\mathrm{HClO}_{4}$ results in a dramatic drop of $S F_{\mathrm{Am} / \mathrm{Eu}}$ from $>154$ in $\mathrm{HNO}_{3}$ down to $\sim 1$ in $\mathrm{HClO}_{4}$.

As anticipated, $\mathrm{CyMe}_{4}-\mathrm{BTPhen}$-functionalized $\mathrm{SiO}_{2}$-coated $\mathrm{MNPs} 4$ exhibited similar extraction 
behaviour (Figure. 5) to 8 in $\mathrm{HClO}_{4}$ solutions showing highest $D_{\mathrm{w}}$ values for both $\mathrm{Am}(\mathrm{III})\left(D_{w \mathrm{Am}}=40 \pm 1\right.$ and $\left.D_{w \mathrm{Am}}=153 \pm 6\right)$ and $\mathrm{Eu}(\mathrm{III})\left(D_{w \mathrm{Eu}}=23 \pm 1\right.$ and $\left.D_{w \mathrm{Eu}}=18 \pm 1\right)$ at $0.001 \mathrm{M}$ and $0.1 \mathrm{M} \mathrm{HClO}_{4}$ concentrations and low $D_{\mathrm{w}}<2.5$ at $1 \mathrm{M} \mathrm{HClO}_{4}$ with no extraction observed for Am(III) or Eu(III) at $4 \mathrm{M}$ $\mathrm{HClO}_{4}$. When compared with its behaviour in $\mathrm{HNO}_{3}$ presented in our earlier paper ${ }^{31}$ (ESI $\dagger$ ), the general trend - decrease of $D_{\mathrm{w}}$ values with increasing acid concentration - is maintained for $\mathbf{4}$ in perchloric acid, too. However, in addition to generally lower values of $D_{w}$ with increasing acid concentration, a significant

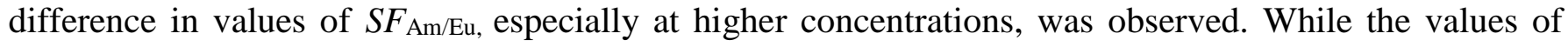
separation factor for 4 in $\mathrm{HNO}_{3}$ were $S F_{\mathrm{Am} / \mathrm{Eu}}=65 \pm 5$ and $S F_{\mathrm{Am} / \mathrm{Eu}}>1300$ at $1 \mathrm{M}$ and $4 \mathrm{M} \mathrm{HNO}_{3}$, respectively, no significant $\mathrm{Am} / \mathrm{Eu}$ separation is observed in $\mathrm{HClO}_{4}$ at these concentrations. This may again be associated with the bidentate properties of the nitrate anion.

To investigate the effect of $\left[\mathrm{HNO}_{3}\right]$ on extraction efficiency further, experiments were conducted at combined $\left[\mathrm{HNO}_{3}+\mathrm{HClO}_{4}\right]$ of $0.001 \mathrm{M}, 0.1 \mathrm{M}, 1 \mathrm{M}$ and $2 \mathrm{M}$. Figure. 6 shows weight distribution ratios for $\mathrm{Am}(\mathrm{III})$ and $\mathrm{Eu}(\mathrm{III})\left(D_{\mathrm{wAm}}\right.$ and $\left.D_{\mathrm{wEu}}\right)$ and separation factors for $\mathrm{Am}(\mathrm{III})$ over $\mathrm{Eu}(\mathrm{III})\left(S F_{\mathrm{Am} / \mathrm{Eu}}\right)$ for CyMe $4-B T P h e n-f u n c t i o n a l i z e d \mathrm{SiO}_{2}$ gel 8 as a function of $\left[\mathrm{HNO}_{3}+\mathrm{HClO}_{4}\right](0.001 \mathrm{M}-2 \mathrm{M})$. Similarly, to the behaviour in $\mathrm{HNO}_{3}$ alone (Figure. 4), the $D_{\mathrm{w}}$ values for both $\mathrm{Am}$ (III) and $\mathrm{Eu}$ (III) initially increased, achieving maximum values at $0.1 \mathrm{M}\left[\mathrm{HNO}_{3}+\mathrm{HClO}_{4}\right]$, and then decreased with increasing $\left[\mathrm{HNO}_{3}+\right.$ $\mathrm{HClO}_{4}$ ], confirming significant role of $\mathrm{NO}_{3}{ }^{-}$in $\mathrm{Am}(\mathrm{III})$ and $\mathrm{Eu}(\mathrm{III})$ separation with immobilized BTPhen ligands.

In conclusion, we report a remarkable capablity of $\mathrm{CyMe}_{4}-\mathrm{BTPhen}$-functionalized $\mathrm{SiO}_{2}$ gel 8 that achieves highly efficient extraction of both minor actinides and lanthanides at low concentrations of $\mathrm{HNO}_{3}$ yet exhibits high selectivity for minor actinides over lanthanides at $4 \mathrm{M} \mathrm{HNO}_{3}\left(S F_{\mathrm{Am} / \mathrm{Eu}}>154\right)$. This constitutes the most efficient partitioning process for minor actinides and lanthanides based on an immobilized ligand system thus far. We conclude that the three bidentate nitrate ions surrounding the $\mathrm{M}(\mathrm{III})$ in the 1:1 complex play an important role in the distinction between the minor actinides and lanthanides and it is the $\mathrm{NO}_{3}{ }^{-}$concentration that is responsible for the selective separation of minor actinides from lanthanides at high $\mathrm{HNO}_{3}$ concentrations. ${ }^{32}$ An interesting finding is the significant difference between the extraction properties of the new CyMe $4-B T P h e n-f u n c t i o n a l i z e d ~ \mathrm{SiO}_{2}$ gel and the CyMe 4 -BTPhen-functionalized $\mathrm{SiO}_{2}$-coated MNPs. Even though both systems involve the same ligand grafted onto the support in an identical manner, their behaviour is markedly different.

\section{ACKNOWLEDGEMENTS}

The authors acknowledge the UK Engineering and Physical Sciences Research Council (EPSRC) and the Grant Agency of the Czech Technical University in Prague (grant No. SGS15/216/OHK4/3T/14) for 
financial support (A.A. and P.D., respectively). Use of the Chemical Analysis Facility (CAF) and Electron Microscopy Laboratory (EMLab) at the University of Reading is gratefully acknowledged.

\section{REFERENCES}

1. J.-H. Lan, W.-Q. Shi, L.-Y. Yuan, J. Li, Y.-L. Zhao, and Z.-F. Chai, Coord. Chem. Rev., 2012, 256, 1406.

2. P. J. Panak, and A. Geist, Chem. Rev., 2013, 113, 1199.

3. A. Leoncini, J. Huskens, and W. Verboom, Chem. Soc. Rev., 2017, 46, 7229.

4. M. P. Jensen, R. Chiarizia, J. S. Ulicki, B. D. Spindler, D. J. Murphy, M. M. Hossain, A. RocaSabio, A. de Blas, and T. Rodríguez-Blas, Solvent Extr. Ion Exch., 2015, 33, 329.

5. $\quad$ L. Xu, A. Zhang, Y. Lu, H. Yang, and Z. Liu, RSC Adv., 2016, 6, 99859.

6. C.-L. Xiao, C.-Z. Wang, L. Mei, X.-R. Zhang, N. Wall, Y.-L. Zhao, Z.-F. Chai, and W.-Q. Shi, Dalt. Trans., 2015, 44, 14376.

7. Q.-R. Huang, J. R. Kingham, and N. Kaltsoyannis, Dalt. Trans., 2015, 44, 2554.

8. J. Veliscek-Carolan, J. Hazard. Mater., 2016, 318, 266.

9. M. Houas, N. Amrani and A. Boucenna, Ann. Nucl. Energy, 2016, 97, 198.

10. M. J. Hudson, L. M. Harwood, D. M. Laventine, and F. W. Lewis, Inorg. Chem., 2013, 52, 3414.

11. J. Bisson, J. Dehaudt, M.-C. Charbonnel, D. Guillaneux, M. Miguirditchian, C. Marie, N. Boubals, G. Dutech, M. Pipelier, V. Blot, and D. Dubreuil, Chem. - A Eur. J., 2014, 20, 7819.

12. M. M. Maiwald, A. T. Wagner, J. Kratsch, A. Skerencak-Frech, M. Trumm, A. Geist, P. W. Roesky, and P. J. Panak, Dalt. Trans., 2017, 46, 9981.

13. A. C. Edwards, P. Mocilac, A. Geist, L. M. Harwood, C. A. Sharrad, N. A. Burton, R. C. Whitehead, and M. A. Denecke, Chem. Commun., 2017, 53, 5001.

14. A. Afsar, D. M. Laventine, L. M. Harwood, M. J. Hudson, and A. Geist, Chem. Commun., 2013, 49, 8534.

15. G. R. Choppin, J. Alloys Compd., 1995, 223, 174.

16. M. Kaneko, S. Miyashita, and S. Nakashima, Inorg. Chem., 2015, 54, 7103.

17. E. Macerata, E. Mossini, S. Scaravaggi, M. Mariani, A. Mele, W. Panzeri, N. Boubals, L. Berthon, M.-C. Charbonnel, F. Sansone, A. Arduini, and A. Casnati, J. Am. Chem. Soc., 2016, 138, 7232.

18. N. J. Williams, J. Dehaudt, V. S. Bryantsev, H. Luo, C. W. Abney, and S. Dai, Chem. Commun., $2017, \mathbf{5 3}, 2744$.

19. F. W. Lewis, L. M. Harwood, M. J. Hudson, M. G. B. Drew, J. F. Desreux, G. Vidick, N. Bouslimani, G. Modolo, A. Wilden, M. Sypula, T. H. Vu, and J. P. Simonin, J. Am. Chem. Soc., 
2011, 133, 13093.

20. D. M. Whittaker, T. L. Griffiths, M. Helliwell, A. N. Swinburne, L. S. Natrajan, F. W. Lewis, L. M. Harwood, S. A. Parry, and C. A. Sharrad, Inorg. Chem., 2013, 52, 3429.

21. A. Geist, U. Müllich, D. Magnusson, P. Kaden, G. Modolo, A. Wilden, and T. Zevaco, Solvent Extr. Ion Exch., 2012, 30, 433.

22. R. Liu, Y. Wei, Y. Xu, S. Usuda, S. Kim, H. Yamazaki, and K. Ishii, J. Radioanal. Nucl. Chem., 2012, 292, 537.

23. Y. Wei, R. Liu, Y. Wu, J. Zu, X. Wang, and Z. Chen, Energy Procedia, 2013, 39, 110.

24. $\quad$ N. Wang, Y. Guo, L. Wang, X. Liang, S. Liu, and S. Jiang, Analyst, 2014, 139, 2531.

25. M. A. Higginson, O. J. Marsden, P. Thompson, F. R. Livens, and S. L. Heath, React. Funct. Polym., 2015, 91-92, 93.

26. J. Veliscek-Carolan, K. A. Jolliffe, and T. L. Hanley, Chem. Commun., 2015, 51, 11433.

27. M. Kaur, H. Zhang, L. Martin, T. Todd, and Y. Qiang, Environ. Sci. Technol., 2013, 47, 11942.

28. S. Ning, Q. Zou, X. Wang, R. Liu, Y. Wei, Y. Zhao, and Y. Ding, J. Radioanal. Nucl. Chem., 2016, 307, 993.

29. A. Afsar, L. M. Harwood, M. J. Hudson, P. Distler, and J. John, Chem. Commun., 2014, 50, 15082

30. A. Afsar, P. Distler, L. M. Harwood, J. John, and J. Westwood, Chem. Commun., 2017, 53, 4010.

31. A. Afsar, L. M. Harwood, M. J. Hudson, P. Distler, and J. John, Chem. Commun., 2014, 50, 15082.

32. F. W. Lewis, L. M. Harwood, M. J. Hudson, M. G. B. Drew, V. Hubscher-Bruder, V. Videva, F. Arnaud-Neu, K. Stamberg, and S. Vyas, Inorg. Chem., 2013, 52, 4993. 